\title{
PLASMA LEVELS OF INTERLEUKIN-6 AND SOLUBLE TUMOR NECROSIS FACTOR RECEPTOR ARE ASSOCIATED WITH MUSCLE PERFORMANCE IN PRE-FRAIL COMMUNITY-DWELLING OLDER WOMEN?
}

\author{
L. Paccini Lustosa ${ }^{1}$, L. Souza Máximo Pereira ${ }^{1}$, P. Parreira Batista ${ }^{2}$, D.A. Gomes Pereira ${ }^{1}$, \\ J.M. Domingues Dias ${ }^{1}$, A. Netto Parentoni ${ }^{3}$
}

\begin{abstract}
Aim: Increased plasma levels of interleukin (IL)-6 and tumor necrosis factor (TNF)- $\alpha$ have been associated with frailty syndrome and reduced muscle strength in older. Sarcopenia influenced loss of mobility and functional independence, and contributed to frailty syndrome. Furthermore, sarcopenia mainly entails a decrease in type II muscle fibers, with consequent loss of muscle power; this could occur as a result of a lack of physical activity. Objective: To examine the correlation of muscular performance and the plasma levels of IL-6 and soluble TNF receptor (sTNFr) in pre-frail community-dwelling women. Methods: The study included 32 pre-frail women ( $\geq 65 \mathrm{ys}$ ). The measurements were plasma concentrations of IL-6 and sTNFr1 (ELISA); muscle strength (isokinetics Biodex System). The muscle resistance program constituted 75\% of maximum load (3 times/week, 10 weeks). Statistical analysis were made through Pearson and Spearman correlation $(\alpha=5 \%)$. Results: There was a significant inverse correlation between sTNFr1 and muscle strength, pre- $(\mathrm{r}=-0.36, \mathrm{P}=.04)$ and post-training $(\mathrm{r}=-0.37, \mathrm{P}=.04)$ and, a significant positive correlation between IL-6 and muscle strength $(r=0.45, \mathrm{P}=.01)$. Conclusion: The correlations found between the inflammatory mediators and the measures of muscular performance evaluated before and after training suggest that, as the muscles increase their ability to generate power, sTNFr concentrations decrease, and the levels of IL-6 increase. Muscle resistance exercises should be encouraged in pre-frail older women to induce the release of cytokines.
\end{abstract}

Key words: Frail, older women, IL-6, sTNFr, exercise.

\section{Introduction}

Sarcopenia is a term used to describe a degeneration of the musculoskeletal system, which can be related to changes in the immune and endocrine systems, among others $(1,2)$. Sarcopenia mainly entails a decrease in type II muscle fibers, with consequent loss of muscle power; this could occur as a result of a lack of physical activity (3-7). Moreover, sarcopenia may have a greater health impact on older women than men, as women have a longer life expectancy and greater rates of morbidity $(7,8)$. Schaap et al $(2006)$ reported a positive correlation between sarcopenia and elevated plasma levels of proinflammatory cytokines, including interleukin-6 (IL-

1. PhD, Prof. Physiotherapy Department, Universidade Federal de Minas Gerais, Belo Horizonte, MG, Brazil; 2. Post-graduate program in Rehabilitation Sciences, Universidade Federal de Minas Gerais, Belo Horizonte, MG, Brazil; 3. PhD, Prof. Physiotherapy Department, Universidade Federal dos Vales do Jequitinhonha e Mucuri, Diamantina, MG, Brazil.

Corresponding Author: Lygia Paccini Lustosa, Av. Prof. Antonio Carlos, 6627 Pampulha - Belo Horizonte - Minas Gerais - Brazil, Cep: 31.270-901 -e-mail: lygia. paccini@gmail.com - tel.: 55 (31) 99831854 / 34094791

Received April 8, 2016

Accepted for publication April 21, 2016
6), C-reactive protein, and tumor necrosis factor-alpha $(\mathrm{TNF}-\alpha)(4)$. Doherty (2003) reported that sarcopenia influenced loss of mobility and functional independence, and contributed to frailty syndrome (6). Frailty syndrome has been described as a clinical, multi-factorial syndrome characterized by 3 distinct actions: deregulation of the neuroendocrine system, deregulation of the immune system, and the induction of sarcopenia $(9,10)$. Thus, sarcopenia may be associated with a sub-threshold state of chronic inflammation that is characteristic of older people (11).

Ferrucci et al (2002) concluded that the reduced ability to perform daily functional activities was associated with high levels of IL- 6 and TNF- $\alpha$, and the loss of muscular strength (12). These authors pointed to the deleterious effect of high concentrations of these cytokines in muscle tissue. Previous studies in our laboratory have demonstrated an inverse correlation between plasma IL-6 levels and muscle strength of lower limbs and hand grip in institutionalized older individuals at rest $(13,14)$. Pereira et al (2009) and Oliveira et al (2008) found an inverse correlation between manual and knee 
extensor muscle strength with plasma levels of IL-6 $(15,16)$. Greiwe et al (2001) reported that an increase in plasma levels of TNF- $\alpha$ is associated with loss of muscle mass, and that concentric resistance exercises could reduce plasma expression of this cytokine in their older participants (17).

In this context, some authors have suggested that physical activity, or a program of specific resistance exercises, could reduce the plasma levels of proinflammatory mediators and possibly reduce the deleterious consequences of these cytokines in musculoskeletal tissue (5, 13, 17-19). The explanation behind this hypothesis relates to the fact that IL-6 can be released by muscle contraction (named myokine), independently of TNF- $\alpha$, thereby inducing the release of other anti-inflammatory cytokines (IL-10 and IL-1ra) that could reduce plasma concentrations of TNF- $\alpha$ (5, 17-20). These assumptions are even more significant when considering the muscular and inflammatory systems of older individuals with frailty syndrome. Moreover, a recent study demonstrated an improvement in muscle strength and function after a resistance exercise program, but no changes in inflammatory mediators following the program. However, discontinuation of this program increased the plasma levels of TNF- $\alpha$ (21).

The objective of this study was therefore to assess the correlation between the muscle strength of knee extensors and plasma indexes of IL-6 and sTNFr1, before and after a resistance exercise program for the lower limbs in prefrail older women.

\section{Methods}

This study was a cross-sectional analysis as part of a randomized, blind, crossover clinical trial approved by the Research Ethics Committee of Universidade Federal de Minas Gerais, decree ETIC 321/2007. The protocol for this study was registered in BioMed Central (BMC) under number ISRCTN62824599 (http: / / www.controlledtrials.com/ISRCTN62824599). All participants signed an informed consent form before starting the study, and were recruited from the clinics of 2 universities, through verbal invitation. After the initial evaluation, the participants started training (3 times/week, for 10 weeks) at $75 \%$ of maximal load. The physiotherapist responsible for the intervention had no knowledge of the evaluations performed. The evaluators had no knowledge of the group to which each participant belonged $(21,22)$.

\section{Sample}

Thirty-two community-dwelling older women (aged 65 years and older) were selected; pre-frail criteria, according to the phenotype proposed by Fried et al (2010) were used.2 All participants answered a questionnaire aimed to characterize the sample in terms of clinical and socio-demographic aspects.
Exclusion criteria were cognitive impairment (Mini Mental State Exam, 1994) (23), orthopedic and neurological diseases that could affect test outcomes, acute inflammatory disease, cancer, and use of drugs that act on the immune system.

\section{Measuring Instruments}

The plasma levels of IL-6 and sTNFr1 were measured by enzyme-linked immunosorbent assay using high sensitivity kits (Quantikine ${ }^{\circledR H S}, \mathrm{R} \& \mathrm{D}$ Systems, Minneapolis, USA). The samples were analyzed by a micro-plate reader set to $490 \mathrm{~nm}$ and corrected for wavelength at $650 \mathrm{~nm}$. The blood sample analyses of plasma concentrations of IL- 6 and sTNFr1 were performed on different days from the muscle tests, with at least a 48-h interval and always in the morning between 8 and $10 \mathrm{am}$. A qualified professional performed the blood collection, following the necessary standards and procedures. Five milliliters of blood was collected and centrifuged at 1,500 rpm for $15 \mathrm{~min}$ to separate the plasma. The plasma was properly identified and stored in a freezer at $-70^{\circ} \mathrm{C}$. The analyses were performed in duplicate, and the results were presented as the average of the 2 measures \pm standard deviation, in $\mathrm{pg} / \mathrm{ml}$.

The muscle performance of the knee extensor muscles were measured by an isokinetic dynamometer (Biodex System 3 Pro $\left.{ }^{\circledR}\right)$ at an angular velocity of $60^{\circ} / \mathrm{s}$ and $180^{\circ} / \mathrm{s}$. At each velocity, 3 training repetitions at sub-maximal effort were used to familiarize the participants with the procedure. The isokinetic evaluation was conducted by measuring 5 and 15 repetitions at maximum effort, at angular velocities of $60^{\circ} / \mathrm{s}$ and $180^{\circ} / \mathrm{s}$, respectively. Participants were motivated during the test by using clapping and verbal encouragement. This standardized version of the test has been used in previous studies [16]. For the analyses, the variable, i.e. work, was standardized by body weight, average power, and peak torque at the angular velocities of $60^{\circ} / \mathrm{s}$ and $180^{\circ} / \mathrm{s}$.

\section{Intervention}

The resistance exercise program was conducted during a period of 10 weeks, with 3 sessions per week. Each session consisted of exercises performed in groups of 4-6 participants, with direct guidance and supervision by a physiotherapist. The exercises targeted the lower limbs, particularly the knee extensors, using open and closed kinetic chain exercises, and a load of $75 \%$ of the participant's maximal load (24). The choice of exercises and program dynamic was based on previous studies (24) and is in agreement with the previously published study protocol (25).

\section{Statistical Analysis}

The sample size was calculated considering a 
confidence interval of $95 \%$, an alpha $(\alpha)$ value of $5 \%$, and a standard error of $20 \%$. To test for the normality of the data, the Anderson Darling test was performed, and a Box Cox transformation for optimal lambda $(\lambda)$ was done for the IL-6 variable as it was not normally distributed. The correlations between variables were made by Pearson and Spearman correlation test. The level of significance was set at $\alpha=5 \%$.

\section{Results}

This study included 32 pre-frail older women. All volunteers were classified as pre-frail, according to criteria described by Fried et al $(1,2)$ and 16 ( 1 in 2 cases) out of the 32 older women evaluated had 2 positive criteria. The most prevalent criteria were reduction in hand grip strength $(43.8 \%)$, low caloric expenditure $(43.8 \%)$, reduction in gait speed $(34.4 \%)$ and reported exhaustion $(25 \%)$. The clinical and demographic characteristics of each group are shown in Table 1.

\section{Table 1}

Demographic and characteristics of participants

\begin{tabular}{lc}
\hline Characteristics & $(\mathbf{n}=\mathbf{3 2})$ \\
Age (yrs), mean (SD) & $72(4)$ \\
BMI (kg/m2), mean (SD) & $29.2(4.2)$ \\
MEEM, mean (SD) & $23(4.8)$ \\
Waist circumference (cm), mean (SD) & $97.9(12.2)$ \\
Waist/hip ratio, mean (SD) & $0.9(0.1)$ \\
White, number (\%) & $10(31.3)$ \\
Mixed race, number (\%) & $20(62.5)$ \\
Married, number (\%) & $12(37.5)$ \\
Widow, number (\%) & $15(46.9)$ \\
\hline Low education level, number (\%) & $26(81.3)$
\end{tabular}

SD, standard deviation; MEEM,Mini Mental State Exam

The analyses of correlation were done before and after the exercises. Before training, there was a poor but significant inverse correlation between the plasma concentration of sTNFr1 and work, which was standardized by body weight in the angular velocity of $180^{\circ} / \mathrm{s}(\mathrm{r}=-0.36, \mathrm{P}=.04)$, peak torque at $180^{\circ} / \mathrm{s}(\mathrm{r}=$ $-0.38, \mathrm{P}=.03)$ and average power at $180^{\circ} / \mathrm{s}(\mathrm{r}=-0.40$, $\mathrm{P}=.02)$, showing that sTNFr1 concentrations were lower when the power, peak torque, and average power increased (Table 2). After exercises, there was a poor but significant inverse correlation between the concentration of sTNFr1 and the measures of standardized work by body weight and average power at $180^{\circ} / \mathrm{s}(\mathrm{r}=-0.37, \mathrm{P}=$ $.04 ; \mathrm{r}=-0.37, \mathrm{P}=.04$, respectively).

Furthermore, there was a positive significant correlation between the plasma concentration of IL- 6 and the peak torque and average power at $60^{\circ} / \mathrm{s}(\mathrm{r}=0.45, \mathrm{P}=$
$.01 ; \mathrm{r}=0.44, \mathrm{P}=.01$, respectively $)$ and at $180^{\circ} / \mathrm{s}(\mathrm{r}=0.46, \mathrm{P}$ $=.01 ; \mathrm{r}=0.37, \mathrm{P}=.04$, respectively). These results showed an increase in IL-6 associated with an increase in peak torque and muscle power, suggesting that this cytokine was released after training (Table 2).

The statistical analyses showed improvement on the muscular power and on the functional capacity after training period, but there was no difference on the inflammatory mediators (data not shown, but previously published). Likewise, after the period of 10 weeks of follow-up there was statistical difference on the sTNFr measures (data not shown, but previously published) (21).

\section{Discussion}

The aim of this study was to assess the correlation between the muscle strength of knee extensors and plasma indexes of IL-6 and sTNFr1 before and after a resistance exercise program for the lower limbs in prefrail older women. The results showed that there was a significant inverse correlation between sTNFr1 and the muscle strength parameters, before and after training. Furthermore, a significant positive correlation between IL-6 and the muscle parameters was detected after training, indicating a probable anti-inflammatory effect of IL-6 released by muscular contraction after resistance exercises.

These findings are in agreement with the results of some authors who suggested using the term myokine for the cytokines that are released by muscle contraction, in particular, IL-6 $(11,19,20)$. According to these authors, in response to muscle contraction, type I and II fibers induce the release of IL-6 $(11,19,20)$. Thus, this cytokine would exert a local effect on the muscle, and peripheral effects via the induction and inhibition of other proand anti-inflammatory cytokines, thereby increasing glucose levels, which are needed for muscle contraction and fat oxidation $(18,19,26,27)$. In this context, there is evidence of an increase in IL-1ra and IL-10 and a reduction in TNF- $\alpha$ after physical exercise, suggesting that exercise has anti-inflammatory effects $(19,21,28)$. Therefore, the significant correlations found in this study are in agreement with the literature, showing that greater muscular performance is associated with lower concentrations of sTNFr and higher concentrations of IL-6.

Another argument about these associations has been suggested, concerning the mechanism of this phenomenon. Febbraio et al (2002) and Petersen et al (2005) showed that the plasma levels of IL-6 tend to increase in response to an increase in adrenal sympathetic response induced by the $\beta$-adrenergic pathway $(11,19)$. Therefore, modifications in the glycogen available for muscle contraction would be sufficient to initiate greater release of IL-6, which, in turn, would alter levels of sTNFr $(11,19,20)$. The present study did not intend to elucidate 
Table 2

Correlation between sTNFr1 and IL-6 with muscular variables, pre- and post-intervention

\begin{tabular}{|c|c|c|c|}
\hline Variable 1 & Variable 2 & $\begin{array}{l}\text { r value (P value) } \\
\text { pre-intervention }\end{array}$ & $\begin{array}{l}\text { r value (P value) } \\
\text { post-intervention }\end{array}$ \\
\hline \multirow[t]{6}{*}{ sTNFr } & Work / body weight at $60^{\circ} / \mathrm{s}$ & $-0.33(.07)$ & $-0.37(.04)^{*}$ \\
\hline & Work / body weight at $180^{\circ} / \mathrm{s}$ & $-0.36(.04)^{*}$ & $-0.35(.05)$ \\
\hline & Peak torque at $60^{\circ} / \mathrm{s}$ & $-0.32(.08)$ & $-0.05(.78)$ \\
\hline & Peak torque at $180^{\circ} / \mathrm{s}$ & $-0.38(.03)^{*}$ & $-0.23(.20)$ \\
\hline & Average power at $60^{\circ} / \mathrm{s}$ & $-0.32(.07)$ & $-0.14(.45)$ \\
\hline & Average power at $180^{\circ} / \mathrm{s}$ & $-0.40(.02)^{*}$ & $-0.37(.04)^{*}$ \\
\hline \multirow[t]{6}{*}{ IL-6 } & Work / body weight at $60^{\circ} / \mathrm{s}$ & $0.21(.25)$ & $0.22(.23)$ \\
\hline & Work / body weight at $180^{\circ} / \mathrm{s}$ & $0.22(.23)$ & $0.19(.27)$ \\
\hline & Peak torque at $60^{\circ} / \mathrm{s}$ & $0.28(.12)$ & $0.45(.01)^{*}$ \\
\hline & Peak torque at $180^{\circ} / \mathrm{s}$ & $0.28(.12)$ & $0.46(.01)^{*}$ \\
\hline & Average power at $60^{\circ} / \mathrm{s}$ & $0.11(.54)$ & $0.44(.01)^{*}$ \\
\hline & Average power at $180^{\circ} / \mathrm{s}$ & $0.17(.34)$ & $0.37(.04)^{*}$ \\
\hline
\end{tabular}

* Significant difference; IL-6, interleukin-6; sTNFr, soluble tumor necrosis factor receptor.

the physiological mechanisms that occur during the release of mediators, but the significant correlations that were found suggest that improved muscular performance is one factor that can modify the plasma concentrations of these inflammatory mediators. However, this hypothesis must be further investigated in future studies with an adequate methodology to explain such mechanisms.

Muscle resistance-training programs have been identified as a positive factor that influences the plasma levels of some cytokines, such as IL- 6 and TNF- $\alpha$ (20). Febbraio et al (2002) and Petersen et al (2005) demonstrated that IL- 6 can be released by muscle activation, independently of TNF- $\alpha$, after performing strenuous exercise that involves large muscle groups $(11,19)$. These authors argued that the muscle could be considered an endocrine organ owing to its participation in the release of cytokines, having consequential endocrine and paracrine actions $(11,18,20,27)$. In this context, IL-6 can induce other anti-inflammatory cytokines (IL-10 and IL-1ra) and thereby inhibit the deleterious effects of TNF- $\alpha$ in muscular tissue $(19,27)$. Therefore, considering the association between muscle strength and inflammatory mediators, our findings suggest that there are modifications occurring in relation these cytokine mediators' causing functional limitations before the clinical detection of loss of strength in older people. These modifications could be triggered and/ or exacerbated by not performing physical activities. However, this phenomenon may also be exacerbated owing to the fluctuating condition and vulnerability of patients with frailty syndrome, which was the target sample of this study.

Finally, studies on the pathogenesis of sarcopenia are not yet conclusive. Several factors may be involved in the loss of muscle mass and strength that are inherent to aging and its association with the inability to perform some activities (2). One of the factors involved, which is currently being studied and may contribute to muscle loss, is the increase in fat between muscle fibers (27). Besides complicating the physiology of muscle contraction, obesity may also contribute to the increased plasma levels of inflammatory mediators $(18,27)$. Even though this study did not aim to verify the correlation between obesity and sarcopenia, the body mass index of the volunteers $(29.3 \mathrm{~kg} / \mathrm{m} 2 \pm 4.1 \mathrm{~kg} / \mathrm{m} 2)$ at basal levels suggests that this variable may have influenced the observed results. Since body mass index was not controlled for different stages of the study, this variable may be a limitation of the study. The observation that the participants were overweight and had a greater abdomen/hip circumference reinforces this hypothesis. However, at this time, a link between high body mass index and muscle strength is a speculative observation that should be investigated in future work.

The correlations found between the inflammatory mediators and the measures of muscular performance evaluated before and after training suggest that, as the muscles increase their ability to generate power, sTNFr concentrations decrease, and the levels of IL-6 increase. Physiotherapists and health professionals who investigate functional and muscular performance in older people must consider the silent activities of inflammatory mediators in their studies.

Acknowledgements: The authors acknowledge the Conselho Nacional de Desenvolvimento Científico e Tecnológico and, Fundação de Amparo à Pesquisa do Estado de Minas Gerais and, Pro-Reitoria de Pesquisa da Universidade Federal de Minas Gerais for supporting this work. The authors certify that they have complied with the ethical guidelines for authorship and publishing in the Journal of Cachexia, Sarcopenia and Muscle 2010, 1:7-8 (von Haeling S, Morley 
JE, Coats AJ and Anker SD). This study was approved by the appropriate ethics comitee (Universidade Federal de Minas Gerais, Belo Horizonte, Brazil) and has therefore been performed in accordance with the ethical standards laid down in the 1964 Declaration of Helsinki and its later amendments. Supported by the Conselho Nacional de Desenvolvimento Científico e Tecnológico and, Fundação de Amparo à Pesquisa do Estado de Minas Gerais and, Pro-Reitoria de Pesquisa da Universidade Federal de Minas Gerais.

Disclosure: No potential conflicts of interest were signed. No commercial party having a direct financial interest in the results of the research supporting this article has or will confer a benefit on the authors or on any organization with which the authors are associated.

\section{References}

1. Fried LP, Ferrucci L, Darer J et al. Untangling the concepts of disability, frailty, and comorbidity: implications for improved targeting and care. J Gerontol Biol Sci Med Sci 2004;59:255-263.

2. Fried LP, Tangen CN, Walston J et al. Frailty in older adults: Evidence for a phenotype. J Gerontol A Biol Sci Med Sci 2001;56:146-156.

3. Cherniack EP, Florez HJ, Troen BR. Emerging therapies to treat frailty syndrome in the elderly. Alter Med Review 2007;12:246-258.

4. Schaap LA, Pluijm SMF, Deeg DJH et al. Inflammatory markers and loss muscle mass (Sarcopenia) and strength. Am J Med 2006;119:526-527.

5. Cesari M, Fielding RA, Pahor $\mathrm{M}$ et al. Biomarkers of sarcopenia in clinical trials - recommendations from the International Working Group on Sarcopenia. J Cachexia Sarcopenia Muscle 2012;3:181-190. DOI: 101007/ s13539-012-0078-2.

6. Doherty TJ. Physiology of aging. Invited review: aging and sarcopenia. J Appl Physiol 2003;95:1717-1727.

7. Clarck BC, Manini TM. Sarcopenia $\neq$ Dynapenia. J Gerontol Med Sci 2008;63A:829-834.

8. Janssen I. The healthcare costs of sarcopenia in the United States. J Am Geriatr Soc 2004;52:80-85.

9. Ershler WB, Keller ET. Aged-associated increased interleukin-6 gene expression, late-life diseases, and frailty. Annu Rev Med 2000;51:245-270.

10. Cohen HJ, Harris T, Pieper CF. Coagulation and activation of inflammatory pathways in the development of functional decline and mortality in the elderly. Am J Med 2003;114:180-187.

11. Febbraio MA, Pedersen BK. Muscle-derived interleukin-6: mechanisms for activation and possible biological roles. Faseb J 2002;16:1335-1347.

12. Ferrucci L, Penninx BWJH, Volpato $S$ et al. Change in muscle strength explains accelerated decline of physical function in older women with high interleukin-6 serum levels. J Am Geriatr Soc 2002;50:1947-1954.

13. Pedersen BK. IL-6 signaling in exercise and disease. Biochem Soc Trans 2007;35:1295-1297.

14. Roubenoff R. Catabolism of aging: is it an inflammatory process? Curr Opin
Nutr Metab Care 2003;6:295-299.

15. Pereira LSM, Narciso FMS, Oliveira MG et al. Correlation between manual muscle strength and interleukin-6 (IL-6) plasma levels in elderly communitydwelling women. Arch Gerontol Geriatr 2009;48:313-316.

16. Oliveira DMG, Narciso FMS, Santos MLAS et al. Muscle strength but not functional capacity is associated with plasma interleukin-6 levels of community-dwelling elderly women. Brazil J Med Biol Res 2008;41:1148-1153.

17. Greiwe JS, Cheng B, Rubin DC et al. Resistance exercise decreases skeletal muscle tumor necrosis factor- $\alpha$ in frail elderly humans. Faseb J 2001;15:475-482.

18. Plomgaard P, Keller P, Keller C et al. TNF- $\alpha$, but not IL-6, stimulates plasminogen activator inhibitor-1 expression in human subcutaneous adipose tissue. J Appl Physiol 2005;95:2019-2023.

19. Petersen AMW, Pedersen BK. The anti-inflammatory effect of exercise. J Appl Physiol 2005;98:1154-1162.

20. Brandt C, Pedersen BK. The role of exercise-induced myokines in muscle homeostasis and the defense against chronic diseases. J Biomed \& Biotech 2010; doi:10.1155/2010/520258.

21. Lustosa LP, Pereira LSM, Coelho FM et al. Impact of an exercise program on muscular and functional performance and plasma levels of interleukin 6 and soluble receptor tumor necrosis factor in prefrail community-dwelling older women: a randomized controlled trial. Arch Phys Med Rehabil 2013;94:660-666.

22. Lustosa LP, Silva JP, Coelho FM et al. Impact of resistance program on functional capacity and muscular strength of knee extensor in pre-frailty community-dwelling older women: a randomized crossover trial. Brazil J Phys Ther 2011;15:318-324.

23. Bertolucci P, Brucki S, Campacci S. O mini-exame do estado mental em uma população geral. Arq Neuropsiquiatr 1994;52:1-7.

24. Eyigor S, Karapolat H, Durmaz B. Effects of a group-based exercise program on the physical performance, muscle strength and quality of life in older women. Arch Gerontol and Geriat 2007;43:259-271.

25. Lustosa LP, Coelho FM, Silva JP et al. The effects of a muscle resistance program on the functional capacity, knee extensor muscle strength and plasma levels of IL-6 and TNF-alpha in pre-frail elederly women: a randomized crossover clinical trial - a study protocol. Trials J 2010;11:82. doi:10.1186/1745-6215-11-82.

26. Reuben DB, Judd-Hamilton L, Harris TB et al. The associations between physical activity and inflammatory markers in high-functioning older persons: MacArthur studies of successful aging. J Am Geriatr Soc 2003;51:1125-1130.

27. Starkie R, Ostrowski SR, Jauffred S et al. Exercise and IL-6 infusion inhibit endotoxin-induced TNF-alfa production in humans. Faseb J 2003;17:884-886.

28. Pereira DS, Mateo ECC, Queiroz BZ et al. TNF- $\alpha$, IL6, and IL10 polymorphisms and the effect of physical exercise on inflammatory parameters and physical performance in elderly women. Age 2013;doi:10.1007/s11357-013-9515-1. 